\title{
Spoilt beauty
}

\section{Michel Boufadel and Hailong Li enjoyed the overwhelming scenery of Prince William Sound, Alaska, while seeking to understand the long-term damage from a 1989 oil spill.}

What was the objective of the work? On 24 March 1989, the oil tanker Exxon Valdez struck a reef and spilt about 40 million litres of oil into Prince William Sound, Alaska. Remediation of the affected beaches was stopped in 1992, on the assumption that the remaining contamination would clear within a few years. But more than 20 years after the spill, significant amounts of oil are still present. We wanted to identify the factors that determine the persistence of oil in the beaches of Prince William Sound.

Why did you choose the particular beaches?

We selected six beaches for the study that either still have considerable oil on them or are in areas known to be of significant ecological value. Two of the beaches (on Smith Island) were exposed to waves and the remaining four were less exposed (on Eleanor Island and Knight Island).

What sorts of data or samples were you after?

We collected sediment and water samples for various analyses to determine the properties of the locations. We also collected samples for analysis in the lab. Every area we touched, we photographed and documented thoroughly to keep detailed records for later when we would be far from the site. Data were collected at many locations with the purpose of measuring various environmental variables, such as pressure, temperature, background concentration and tracer concentration.

Did you encounter any difficulties? Overall the operation went smoothly, but we often found that a lack of workers would change our plans. You can never have too much help when working on these beaches, especially when working against the rising and falling tides, which move incredibly fast in Prince William Sound. Some of the team members got trapped by the tide on a beach on Eleanor Island that

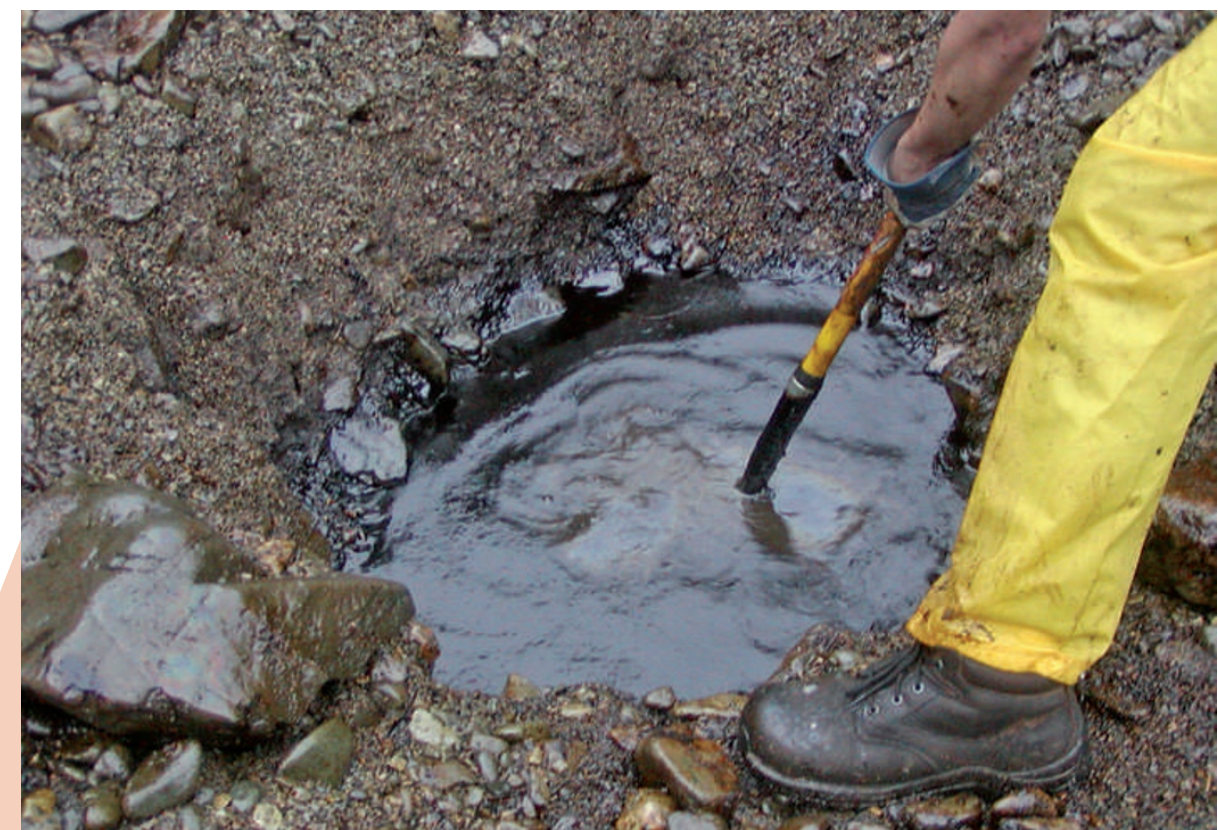

Digging oil. Pits on two-layered beaches in Prince William Sound, Alaska, revealed persistent oil contamination originating from the Exxon Valdez oil spill in 1989.

has a steep cliff behind it! Fortunately, the skiff arrived on time to carry them off of the beach.

Did you have interesting encounters with animals?

We saw a good amount of native wildlife. While on the boat we spotted humpback whales a few times, porpoises and an orca or two. We also saw seals, eagles, numerous fish types, and occasionally from a distance, black bears.

\section{Any low points, close misses?}

The elements sometimes created a work environment that was not the most enjoyable to be in, but that was countered by days of excellent weather and some great views. Something else that caused a few hiccups was when we discovered that the screen placed on the intake of the pump was getting clogged rapidly when extracting water from the sea, and subsequently restricted the flow. We solved this problem by using an empty barrel as a 'stilling basin' causing the sediments to settle to the bottom of it while extracting water from the top.
What was your personal highlight of the expedition?

Being in Alaska is a great experience in itself, the beauty of the area is incredible. When we struck the oil in the ground with our shovels and noticed the severity of the situation, we all realized how important our work was. And each day, everyone looked forward to getting back to the boats to eat. We had great cooks, and the hospitality from them and the rest of the crew made the time offshore enjoyable and gave us all moments to relax.

Did the trip give you any ideas for future research projects?

As global warming takes its toll, shipping lanes will shift northward and the risk of oil spills in the Arctic Circle will increase. It will be important to conduct ecological studies around the Arctic Circle to prepare contingency plans for accidental oil spills.

This is the Backstory to the work by Hailong Li and Michel Boufadel, published on page 96 of this issue. 